glucocorticoids on structure and function of adult rat jejunum. Am. J. Physiol.. 241: G 306 (1981).

38. Tutton. P. J. M.: Proliferation of epithelial cells in the jejunal crypts of adrenalectomized and adrenocortical hormone-treated rats Virchows Arch. B. Cell. Pathol.. 13: 227 (1973).

39. Tye. L. M. and Burton. A. F.: Effects of dexamethasone on fetal mouse development. Biol. Veonate, 38: 260 (1980).

4(). The authors wish to thank Nadine De Kevzer and Monique Boclens for their expert technical assistance.
41. The authors are very grateful to Dr. Penelope Brock for her helpful comments on the manuscript.

42. Requests for reprint should be addressed to: Jean-Paul Buts, M. D., Department of Pediatrics. University of Louvain. Clinique Saint-Luc, 10 avenue Hippocrate, B-1200 Brussels. Belgium.

43. This research was supported by grant no 3-4551/82 from the FRSM (Fonds de Recherche Scientifique Médicale) Belgium.

44. Received for publication September 24. 1982

45. Accepted for publication May 12,1983.

\title{
Effect of External Inspiratory Loading on Ventilation of Premature Infants
}

\author{
SORAYA ABBASI, ${ }^{(30)}$ SHANAZ DUARA, THOMAS SHAFFER, AND WILLIAM W. FOX \\ Department of Pediatrics, Pennsylvania Hospital and the University of Pennsylania, School of Medicine, \\ Philadelphia, Pennsylvania [S.A.]; Department of Pediatrics, University of Marvland, Baltimore, Marvland \\ [S.D.]: Department of Physiology, Temple University School of Medicine, Philadelphia, Pennsylvania [T.S./; and \\ Department of Pediatrics, The Children's Hospital of Philadelphia and the University of Pennsylvania School of \\ Medicine, Philadelphia, Pennsylvania, USA [W.W.F.]
}

\begin{abstract}
Summary
The ventilatory response of 11 growing premature infants to external inspiratory resistive loads was evaluated. Air flow, tidal volume, minute ventilation, inspiratory duration and total breath duration were measured before and after application of a flow resistive load. A significant $(P<0.001)$ immediate decrease in minute ventilation and tidal volume was observed in all infants after load application. Minute ventilation and tidal volume remained decreased throughout the 10 -min study period. Minute ventilation and tidal volume for the group decreased to 48 and $50 \%$ of control mean value, respectively. In addition, there was a significant $(P<0.001)$ sustained increase in inspiratory time resulting in an increase in the ratio of inspiratory time/total respiratory time.
\end{abstract}

\section{Abbreviation \\ $\mathrm{T}_{\mathrm{I}} / \mathrm{T}_{\mathrm{T}}$, respiratory timing expressed as inspiratory time divided by total respiratory time}

Recent monitoring techniques have demonstrated that airway obstruction occurs frequently in premature neonates recovering from respiratory disease $(1,28)$. Upper airway obstruction has been shown to produce significant ventilatory deficiency particularly in preterm infants $(4,14)$ and has been suggested as one of the etiologies of apnea $(14,24)$. Several investigators have shown that upper airway obstruction can result from passive or active neck flexion, occlusion of the oropharynx by the tongue due to sleep-induced relaxation of genioglossus muscle, or edema of the upper airway in infants with nasopharyngitis $(20,25,27)$.

Although airway obstruction can occur frequently in premature infants, there is little information on the physiologic response to either partial or complete obstruction. The ventilatory response of premature infants to a flow resistive load to simulate partial airway obstruction was studied (6); however, these infants were only exposed to this load for the duration of one breath. In order to understand the role of different types of flow resistive loads in infants, it may be necessary to evaluate inspiratory and expiratory loads separately.

The purpose of this study is to evaluate the immediate and sequential effects of an external inspiratory flow resistance on the ventilatory response of growing premature infants. These data should be useful in understanding compensatory mechanisms involved in partial airway obstruction.

\section{MATERIALS AND METHODS}

Eleven infants were studied after recovery from respiratory disease. They did not have cardiorespiratory diseases at the time of the study or any evidence of intracranial hemorrhage during the course of hospitalization. The infants had estimated gestational ages ranging from $28-36 \mathrm{wk}$, a mean birth weight of 1.50 $\pm 0.13 \mathrm{~kg}$, and mean study age of $4.15 \pm 1.10$ postnatal wk. They were studied in sleep approximately $30 \mathrm{~min}$ after a feeding.

Ventilatory response was evaluated with the infant in the supine position breathing room air, through a soft rubber face mask (Ohio Products), which tightly covered the infant's mouth and nose. A heated pneumotachygraph (Hewlett-Packard 21069) was used to measure air flow. The pneumotachygraph was attached to the face mask and a one-way nonrebreathing $\mathrm{T}$-valve. Flow signals were integrated to produce tidal volume by a Hewlett-Packard flow-integrator (NO. 8802A). The end tidal $\mathrm{CO}_{2}$ was measured by a Cavitron Anard Gas Analyzer at a pump flow rate of $100 \mathrm{ml} / \mathrm{min}$ through continuous sampling from the mask air. A Litton Oxymonitor (Model No. 23604803) was used for transcutaneous oxygen tension monitoring.

A standard length endotracheal tube, $2.5 \mathrm{~mm}$ in diameter, was used for the inspiratory flow resistive load. The endotracheal tube was narrowed by a central adjustable screw clamp, $3 \mathrm{~mm}$ wide, to produce different resistances (18). For the study, each infant was evaluated with two different resistances. These resistances $\left(\mathrm{R}_{1}=100 \mathrm{~cm} \mathrm{H} \mathrm{H}_{2} \mathrm{O} \cdot \mathrm{L}^{-1} \cdot \mathrm{s}^{-1}\right.$ and $\mathrm{R}_{2}=150 \mathrm{~cm} \mathrm{H} \mathrm{O} \cdot \mathrm{L}^{-1}$. $\mathrm{s}^{-1}$ at $1 \mathrm{~L} / \mathrm{min}$ flow rate) were selected as a mid and mid-high resistive loads by a preliminary testing of 10 different resistances 
in preterm infants to determine maximum tolerated air flow resistive load for a period of $30 \mathrm{~min}$. The flow resistance of each load was determined by measurement of the generated pressure difference across the resistor created by air flow in the range of $0-5 \mathrm{~L} / \mathrm{min}$. These simultaneous air flow and pressure measurements were recorded on a Hewlett-Packard X-Y recorder. The resistance of each load was linear up to flow rates above those encountered experimentally $(2 \mathrm{~L} / \mathrm{min})$. The resistance was added to the inspiratory limb of the non-rebreathing valve at end expiration, and the expiratory limb remained open to room air. Mask and system dead space varied slightly from patient to patient depending on facial configuration and it was approximately $4.5 \mathrm{ml}$. The total resistance of the circuit was calculated to be $15 \mathrm{~cm} \mathrm{H} \mathrm{H}_{2} \mathrm{O} \cdot \mathrm{L}^{-1} \cdot \mathrm{s}^{-1}$, at a flow rate of $1 \mathrm{~L} / \mathrm{min}$.

During a control period of $5 \mathrm{~min}$, the infants breathed through the face mask and circuit while ventilatory parameters and endtidal $\mathrm{CO}_{2}$ were recorded. Flow resistance was then added to the inspiratory limb of the non-rebreathing valve for $10 \mathrm{~min}$. A minimum of $2 \mathrm{~h}$ was allowed for recovery between two different resistances $\left(R_{1}\right.$ and $\left.R_{2}\right)$.

Tidal volume, flow rate, esophageal pressure, respiratory frequency, $\left(T_{1} / T_{T}\right)$ were calculated from the tracing before, immediately, 5, and $10 \mathrm{~min}$ after application of resistances in steady state respiration. Minute ventilation was the product of tidal volume and respiratory frequency. The ventilatory parameters were calculated as a mean of five successive breaths.

The infants were monitored throughout the study period with a cardiorespiratory monitor, transcutaneous oxygen monitor and end-tidal $\mathrm{CO}_{2}$ monitor. All signals were displayed on an 8channel recorder (Hewlett-Packard Model No. 7758B).

All measurements of ventilatory parameters were made during quiet sleep. Sleep state was monitored in these infants using described behavioral signs of body movements along with a biocular recording of eye movements (23). Rapid eye movement sleep was characterized by presence of rapid eye movements, rapid fine twitching movement of the face and hands, and irregularity of tidal volume and respiratory frequency. Quiet (non-REM) sleep was characterized by the absence of both rapid eye movements and somatic activity, and by regular tidal volume and respiratory frequency.

The protocol for this experiment was approved by the Committee on Investigation and Activity Involving Human Subjects. Informed consent was obtained from parents before the study. Data were analyzed and comparisons made between control and experimental periods using the paired Student's $t$ test.

\section{RESULTS}

Table 1 summarizes control respiratory function data for all 11 patients. Tidal volume, respiratory frequency, minute venti- lation, inspiratory and expiratory flow, and end-tidal (alveolar $\mathrm{CO}_{2}$ ) are consistent with values previously reported for infants of similar gestational age and weight (19).

Infants tolerated the study well and did not demonstrate changes in heart rate, transcutaneous $\mathrm{PO}_{2}$ or sleep state after applying the mask with or without resistances. No infant had apnea (cessation of breathing for more than $15 \mathrm{~s}$ ) during the study period. A typical response to inspiratory loading (low resistance, $R_{1}$ ) is shown in Figure 1 (Patient No. 5). As shown in this tracing, after application of the resistance, the first subsequent breath demonstrated a decrease of $4.0 \mathrm{ml}$ in tidal volume from a mean control value of $10.0 \mathrm{ml}$ to a tidal volume of 6.0 ml. Tidal volume decreased further to a mean of $4.0 \mathrm{ml}$ on the next four subsequent breaths. Mean flow demonstrated a similar pattern with an initial decrease to $1.80 \mathrm{~L} / \mathrm{min}$ on the first postresistance breath from a control value of $1.95 \mathrm{~L} / \mathrm{min}$ and a subsequent further decrease to a mean of $1.05 \mathrm{~L} / \mathrm{min}$ for the next four successive breaths. Mean end-tidal $\mathrm{CO}_{2}$ demonstrated no significant change from pre-resistance value of $34.0 \pm 3.3$ $\mathrm{mm} \mathrm{Hg}$ during the application of the inspiratory resistive load.

Figure 2 ( $\mathrm{A}$ and $\mathrm{B}$ ) demonstrates immediate, 5-, and 10-min changes in mean \pm SEM values for tidal volume and minute ventilation for all patients after application of inspiratory resistive loading. As shown, there was both an immediate (first five breaths) and sustained (up to $10 \mathrm{~min}$ ) significant decrease of $50 \%$ $(P<0.01)$ in both tidal volume and minute ventilation. Tidal volume decreased from a mean control value of $12.9 \mathrm{ml}$ to 6.7 $\mathrm{ml}$ immediately, $8.1 \mathrm{ml} 5 \mathrm{~min}$ and $7.8 \mathrm{ml} 10 \mathrm{~min}$ after resistive load application $\left(R_{1}\right)$. After $2 \mathrm{~h}$, the application of $\mathrm{R}_{2}$ resulted in a decrease from a control value of 13.7 to $6.8 \mathrm{ml}$ immediately, $7.2 \mathrm{ml}$ at $5 \mathrm{~min}$ and $7.4 \mathrm{ml}$ at $10 \mathrm{~min}$. Minute ventilation decreased from a mean control value of $723.9 \mathrm{ml}$ to $344.5 \mathrm{ml}$ immediately, $428.1 \mathrm{ml}$ at $5 \mathrm{~min}$, and 396.6 at $10 \mathrm{~min}$ after resistive load application $\left(R_{1}\right)$. The application of $R_{2}$ resulted in a decrease from a control value of $787.9 \mathrm{ml}$ to $344.5 \mathrm{ml}$ immediately, $377.5 \mathrm{ml}$ at $5 \mathrm{~min}$ and $374.5 \mathrm{ml}$ at $10 \mathrm{~min}$.

Figure 3 ( $A$ and $B$ ) demonstrates mean \pm SEM values for peak inspiratory and expiratory flow responses in all babies after inspiratory resistive loading. There was a significant immediate and sustained decrease in inspiratory flow for both resistances $(P$ $<0.001)$. Inspiratory flow decreased from a mean control value of $1.95 \mathrm{~L} / \mathrm{min}$ to $0.65 \mathrm{~L} / \mathrm{min}$ immediately, $0.72 \mathrm{~L} / \mathrm{min}$ at $5 \mathrm{~min}$, and $0.63 \mathrm{~L} / \mathrm{min}$ at $10 \mathrm{~min}$ after resistive load application $\left(\mathrm{R}_{1}\right)$. After a 2 -h recovery period, the application of $R_{2}$ resulted in a decrease in inspiratory flow from a control value of $2.12 \mathrm{~L} / \mathrm{min}$ to $0.53 \mathrm{~L} / \mathrm{min}$ immediately, $0.54 \mathrm{~L} / \mathrm{min}$ at $5 \mathrm{~min}$, and $0.64 \mathrm{~L} /$ min at $10 \mathrm{~min}$. Expiratory flow (Figure $4 \mathrm{~B}$ ) was decreased immediately and at 10 min as compared with control for $R_{1}$ and at 5 and $10 \mathrm{~min}$ for $R_{2}$. This decrease in expiratory flow, although significant at this point of time, was only approximately a $30 \%$ decrease compared with control value.

Table 1. Control pulmonary function data of 11 infants studied with inspiration flow resistances

\begin{tabular}{|c|c|c|c|c|c|c|c|c|}
\hline Infants & $\begin{array}{c}\text { Study } \\
\text { weight } \\
(\mathrm{kg})\end{array}$ & $\begin{array}{c}\mathrm{V}_{\mathrm{T}} \\
(\mathrm{ml})\end{array}$ & $\begin{array}{c}\dot{\mathrm{V}}_{\mathrm{E}} \\
(\mathrm{ml} / \mathrm{min})\end{array}$ & $\mathrm{T}_{\mathrm{I}} / \mathrm{T}_{\mathrm{T}}$ & $\begin{array}{c}\text { Frequency } \\
\text { (breath/min) }\end{array}$ & $\begin{array}{c}\dot{\mathrm{V}}_{\text {insp }} \\
(\mathrm{L} / \mathrm{min})\end{array}$ & $\begin{array}{c}\dot{\mathrm{V}}_{\exp } \\
(\mathrm{L} / \mathrm{min})\end{array}$ & $\begin{array}{c}\mathrm{P}_{\mathrm{ET}} \mathrm{CO}_{2} \\
\text { (Torr) }\end{array}$ \\
\hline 1 & 1.78 & 21. & 906.7 & 0.40 & 43 & 1.65 & 1.35 & 45.0 \\
\hline 2 & 1.70 & 12.2 & 604.9 & 0.45 & 49 & 1.80 & 1.50 & \\
\hline 3 & 2.50 & 10.9 & 578.6 & 0.45 & 53 & 2.10 & 2.10 & 22.0 \\
\hline 4 & 2.01 & 17.0 & 910.6 & 0.51 & 53 & 3.30 & 1.95 & 32.1 \\
\hline 5 & 1.41 & 10.5 & 577.9 & 0.46 & 55 & 1.36 & 0.93 & \\
\hline 6 & 1.33 & 11.8 & 745.1 & 0.49 & 63 & 1.87 & 1.3 & 29.2 \\
\hline 7 & 1.45 & 9.1 & 371.3 & 0.41 & 41 & 0.98 & 0.90 & 24.6 \\
\hline 8 & 1.91 & 10.8 & 632.1 & 0.45 & 58 & 1.75 & 1.28 & 28.3 \\
\hline 9 & 1.70 & 10.8 & 637.2 & 0.46 & 59 & 1.98 & 1.86 & 47.0 \\
\hline 10 & 1.60 & 10.2 & 577.0 & 0.38 & 56 & 1.80 & 1.39 & 43.2 \\
\hline 11 & 1.75 & 18.0 & 1026.0 & 0.51 & 57 & 2.89 & 3.00 & 43.9 \\
\hline Mean & 1.74 & 12.9 & 687.95 & 0.44 & 53.36 & 1.95 & 1.59 & 34.5 \\
\hline$\pm \mathrm{SEM}$ & 0.10 & 1.1 & 57.54 & 0.01 & 6.70 & 0.19 & 0.18 & 3.3 \\
\hline
\end{tabular}




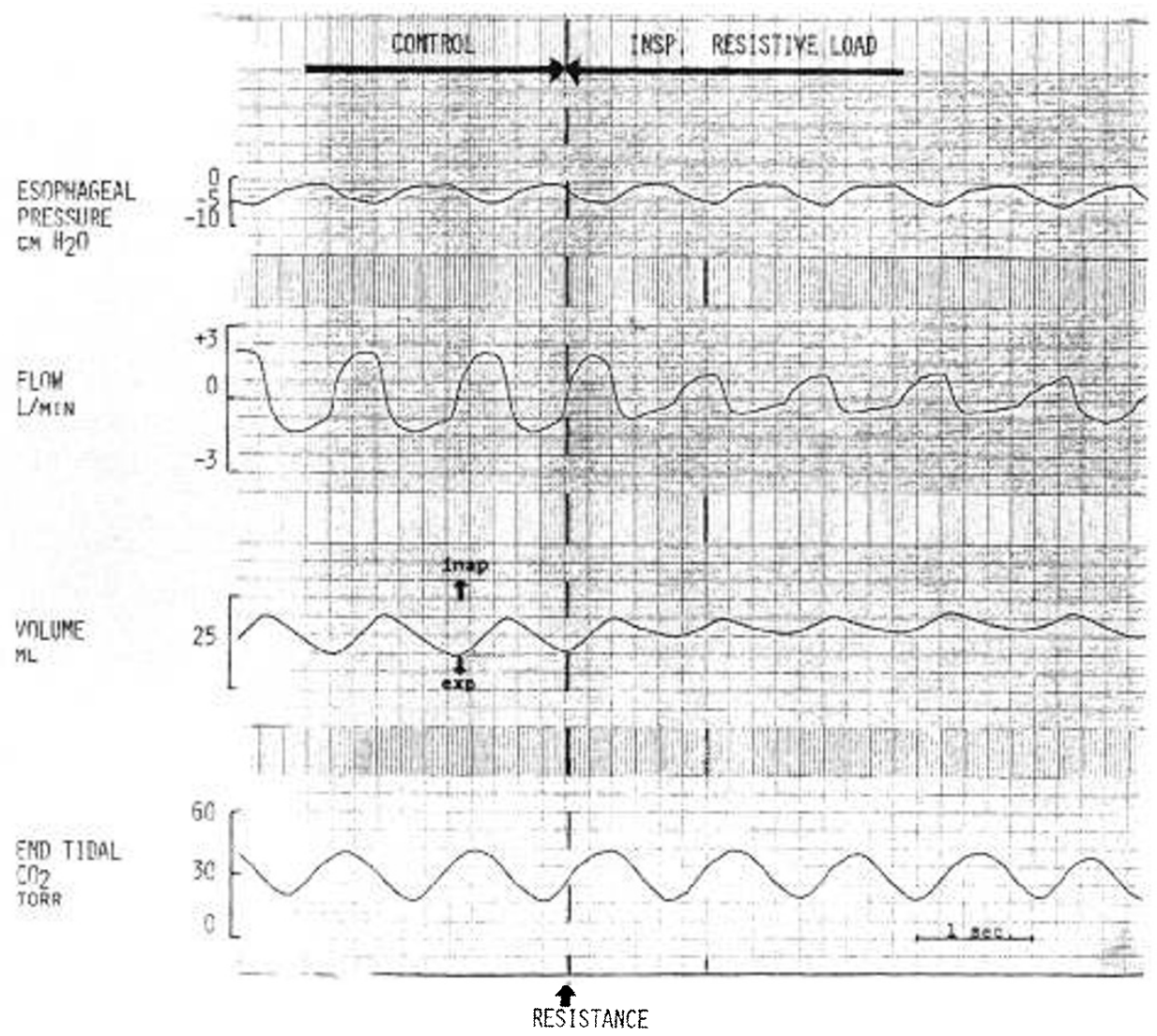

Fig. 1. Typical tracing (patient no. 5) demonstrating esophageal pressure, flow, volume, and end-tidal $\mathrm{CO}_{2}$ response to application of an external inspiratory flow resistance (low resistive load, $R_{1}$ ).
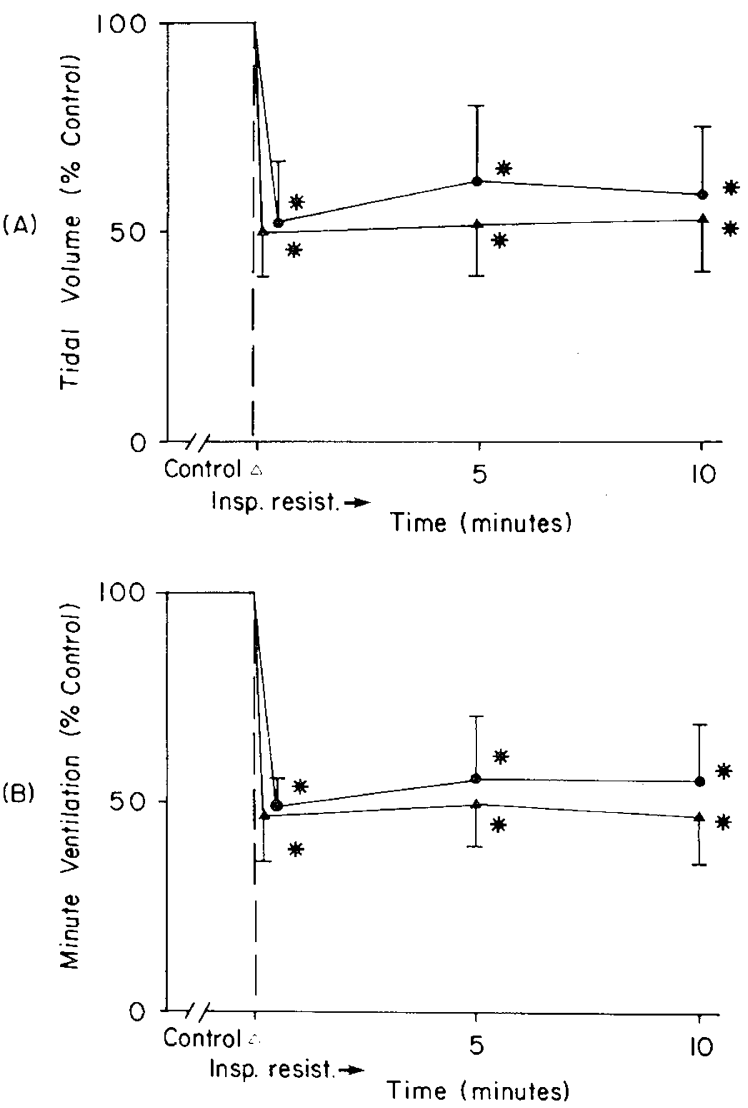

Fig. 2. (A) Percentage immediate and sustained reduction of tidal volume relative to control value after application of two different sizeinspiratory flow resistances. $(B)$ Reduction of minute ventilation relative to control after two different size inspiratory flow resistances. (mean \pm SEM value; $\bullet=\mathrm{R}_{1}, \boldsymbol{\Delta}=\mathrm{R}_{2},{ }^{*} P<0.001$ ).
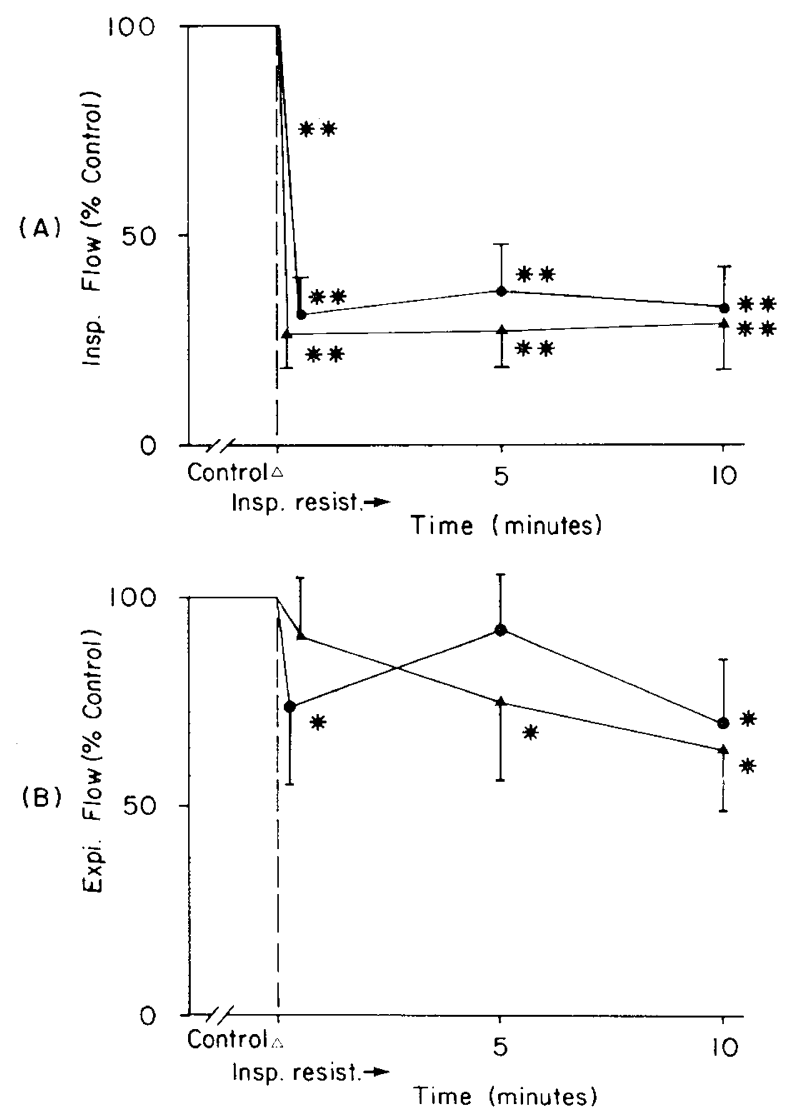

Fig. 3. (A) Percentage immediate and sustained reduction of inspiratory air flow relative to control value after application of two different size resistances. $(B)$ Reduction of expiratory flow relative to control after two different size inspiratory flow resistances (mean $\pm \mathrm{SEM} ; \boldsymbol{=}=\mathrm{R}_{1}$; $\Delta$ $\left.=\mathrm{R}_{2},{ }^{*} \mathrm{p}<0.05 ;{ }^{* *} P<0.001\right)$. 


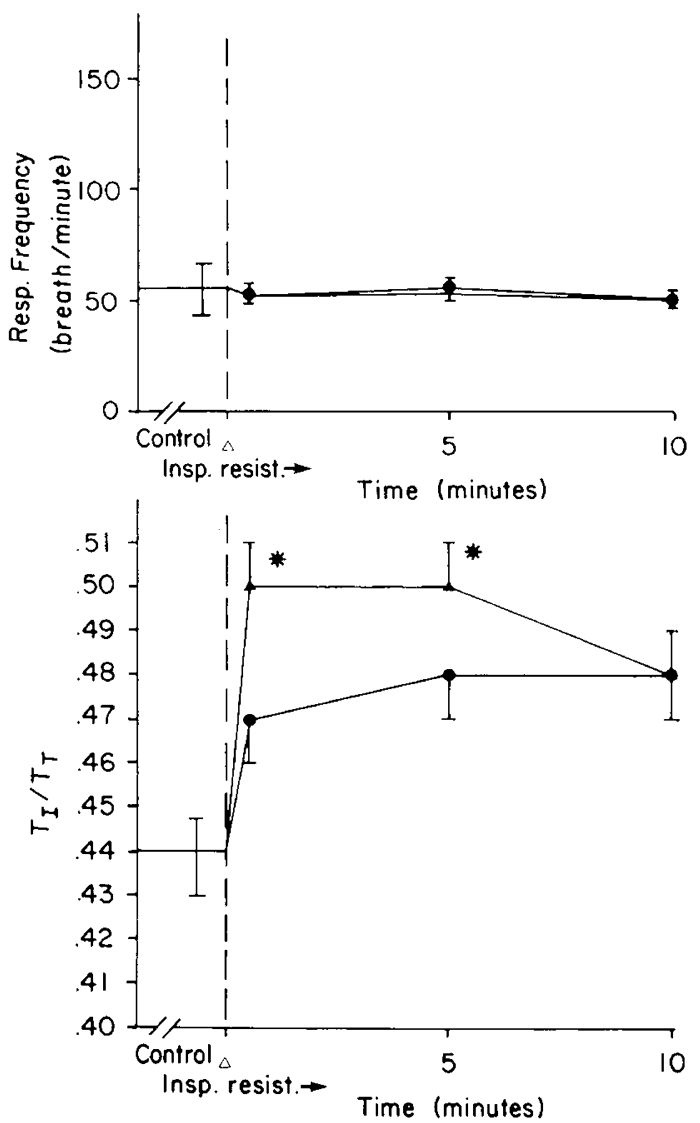

Fig. 4. (A) Shows minimal changes in respiratory frequency after load application. $(B)$ Change in inspiratory time/total respiratory time $\left(\mathrm{T}_{\mathrm{l}} /\right.$ $\left.\mathrm{T}_{\mathrm{T}}\right)\left(\right.$ mean $\pm \mathrm{SEM}$ values; $\bullet=\mathrm{R}_{1} ; \boldsymbol{\Delta}=\mathrm{R}_{2}$ ).

Figure $4(\mathrm{~A}$ and $\mathrm{B})$ shows responses in mean \pm SEM values for respiratory frequency and $T_{I} / T_{T}$ after application of inspiratory resistances. Respiratory frequency did not change significantly either immediately or at 5 and 10 min after application of the inspiratory resistances. As would be expected from an added inspiratory flow resistance, inspiratory time was prolonged resulting in a significant increase in $\mathrm{T}_{\mathrm{I}} / \mathrm{T}_{\mathrm{T}}$ immediately and at 5 min after application of $R_{2}$.

End-tidal $\mathrm{CO}_{2}$ increased slightly ( 34.5 to $35.7 \mathrm{~mm} \mathrm{Hg}$ ) during load application. Transcutaneous oxygen readings did not change significantly from the control value throughout the study. The ventilatory patterns returned to the control level of ventilation within two to three breaths after removal of the resistance from the circuit.

\section{DISCUSSION}

This study demonstrates that preterm infants who have recovered from cardiopulmonary disease exhibit an immediate and sequential ventilatory response after the application of an inspiratory flow resistive load. This response was characterized by a decrease in tidal volume, minute ventilation and expiratory flow, with no significant change in respiratory frequency. In addition, there was a significant increase in inspiratory time. Previous investigations with expiratory flow resistance in neonates have demonstrated increases in lung volume and transient changes in tidal volume and breathing rates (18). These changes are similar to the breathing response seen after intermittent mandatory ventilation breaths in neonates (22). In contrast, we found that the application of an inspiratory flow resistance results in a sustained reduction in tidal volume and minute ventilation. The immediate decrease in tidal volume and minute ventilation is an expected response after the application of an inspiratory resistive load and has been demonstrated in both conscious adult subjects and laboratory animals $(2,8,17)$. This reduction of tidal volume and minute ventilation is proportional to the size of the inspiratory resistive load with less change in ventilation with small loads and greater decrease in ventilation by larger load ( 3 , 12, 29).

The sustained reduction in tidal volume and minute ventilation with load application has not been shown previously. Conscious adult subjects manifest an increase in tidal volume above that of first breath with each successive breath after inspiratory load application. This increase in effort to maintain tidal volume breathing through the inspiratory resistor is called load compensation. The compensation of adults to added inspiratory loads starts with the first loaded breath $(1,9)$. The compensation of the first breath is believed to be due to intrinsic properties of the respiratory muscles (1). The mechanism of progressive load compensation is not clear. Progressive increases in tidal volume after loads has been attributed to the load compensatory reflexes originating from the chest wall. Peripheral chemoreceptor stimulation by hypoxia has also been suggested as a mechanism of load compensation over a period of time. This hypothesis is based on the observation that subjects who breathe higher concentrations of oxygen than room air had less progressive increases in tidal volume than subjects who breathed room air (16). Also this increase in tidal volume of subsequent breaths was completely abolished by breathing $100 \%$ oxygen in a number of studies $(9,11)$.

In contrast to conscious adults and laboratory animals, the study infants did not manifest a progressive increase in tidal volume after load application; however, this lack of progressive compensation in our study infants is similar to the response of adult men and study animals under light anesthesia breathing spontaneously through a tubular resistor (28). Added inspiratory resistance induced an increase in the neural stimuli to inspiratory muscles in adult laboratory animals even when chemical stimulus to breathing was held constant (15). Anesthetized animals did not show any changes in neural stimulus, which emphasizes the importance of higher brain centers and level of consciousness in increasing inspiratory effort to maintain adequate tidal volume.

It has been shown that changes in consciousness affect pharyngeal dimension in adults and infants $(20,21)$. Obstructive apnea is seen in association with naturally producing narrowing of naso and propharynx with neck flexion in sleeping preterm infants and in infants with congenital retrognathia (7). For these reasons and because newborn infants can spend up to $80 \%$ of each 24-h period in sleep, we elected to study our infants in sleep.

The end-tidal $\mathrm{CO}_{2}$ and transcutaneous oxygen monitor did not change significantly with added inspiratory resistance although there was a reduction in minute ventilation. Other investigators have observed this lack of expected elevation of blood $\mathrm{CO}_{2}$ with reduction in minute ventilation in infant and animal studies using arterial catheters for blood gas sampling. This maintenance of blood $\mathrm{CO}_{2}$ tension in face of decreased minute ventilation has been hypothesized by these authors to be the result of more efficient ventilation, a decrease in physiologic dead space $(5,13)$ or changes in metabolic rate. We conclude that in these infants, as in adults under light anesthesia, the respiratory control system does not react to an increase in inspiratory resistance by increasing respiratory effort to return tidal volume to control levels.

\section{REFERENCES AND NOTES}

1. Altose M D Kelsen, S. G and Cherniack, N. S. Respiratory responses to changes in airflow resistance in conscious man. Resp. Physiol., 36: 261 (1979).

2. Altose, M. D.. Kelsen, S. G., and Cherniack, N. S.: Respiratory response to change in outflow resistance in conscious man. Resp. Physiol.. 36: 249 (1979).

3. Altose, M. D., McCauley, W. C., Kelsen, S. G., and Cherniack, N. S.: Effects of hypercapnia and inspiratory flow resistive loading on respiratory activity in chronic airways obstruction. J. Invest., 59: 500 (1977). 
4. Ariagno. R. L.. Guilleminault. C.. and Nagel, L. E.: Mixed and obstructive sleep apnea in 3-month old control and near miss for sudden infant death syndrome infants. Pediatr. Res., I2: 519 (1978).

5. Blanco. C.. Hanson, M., Johnson, P.. and Rigatto, H.: The pattern of breathing of kittens during hypoxia. Pediatr. Res., 15:652 (1981)

6. Boychuk, R. B., Seshia, M. M. K.. and Rigatto, H.: The immediate ventilatory response to added inspiratory elastic and resistive loads in preterm infants. Pediatr. Res., 11: 276 (1977)

7. Brouillette, R. T. and Thach, B. T.: A neuromuscular mechanism maintaining extrathoracic airway patency. J. Appl. Physiol.. 46: 772 (1979).

8. Campbell. E. J., Dickinson, O. P., and Howel, B. L.: The immediate effects of added loads on the inspiratory musculature of the rabbit. J. Physiol., 172; 321 (1964).

9. Campbell. E. J.. Dinnick, O. P.. and Howel, B. L.: The immediate effect of added load on the breathing of man. J. Physiol., 156: 260 (1964).

10. Dransfield. D. A., Lewis. J., and Fox, W. W.: Efficiency of air flow measurements by nasal determination without oral measurements in neonatal apnea. Pediatr. Res., 14:595 (1980)

11. Frantz. J. D. and Milic-Emili, J.: The progressive response of the newborn infant to added respiratory loads. Resp. Physiol.. 233 (1975).

12. Freedman, S. and Campbell, E. M. J.: The ability of normal subjects to tolerate added inspiratory loads. Resp. Physiol.. 10:213 (1970).

13. Goldman, S. L., Brady, J. P., Chir, B.. and Dumpit, F. M.: Increased work of breathing associated with nasal prongs. Pediatrics, 64: 160 (1979).

14. Guilleminault. C.. Ariagno. R.. Korobikin. R.. Nagel. L., Baldwin, R., Coons, S., and Owen. M.: Mixed and obstructive sleep apnea and near miss for sudden infant death syndrome: 2. Comparison of near miss and normal control infants by age. Pediatrics, 64: 882 (1979)

15. Isaza, G. D., Posner, J. D., Altose, M. D., Kelsen, S. G., and Cherniack, N. S.: Airway occlusion pressures in awake and anesthetized goats. Resp. Physiol., 27: 87 (1976).

16. Margaria. S. I. Iscoe, S., Pengelly, J., Couture. M. D., and Milic-Emili, J.: Immediate ventilatory response to elastic loads and positive pressure in man. Resp. Physiol.. 37 (1973).

17. Milic-Emili. J. and Pengelly, J.: Ventilatory effect of mechanical loading. In: E. J. M. Campbell, E. Agastoni, and J. Newsom-Davis: The Respiratory
Muscles. (Lloyd Duke, London, 1970)

18. Moomiian A. S Schwartz J G. Wagaman M. J Shutack, J G Shaffer, T. H. and Fox. W. W.: The effect of external expiratory resistance on lung volume and pulmonary function in the neonate. J. Pediatr., 96: 908 (1980).

19. Nelson, N. M.. Prod'hom, L. S., Cherry, R. B., Lipsitz, P. L., and Smith, C. A.: Pulmonary function in the newborn infant. I. Methods: Ventilation and gaseous metabolism. Pediatrics, 30: 963 (1962).

20. Remmers, J. E., de Groot, W. J., Sauerland, E. M., and Anch, A. M.: Pathogenesis of upper airway occlusion during sleep. J. Appl. Physiol., 44: 931 (1978).

21. Sauerland, E. K. and Harper, R. M.: The human tongue during sleep: Electromyographic activity of the genioglossus muscle. Exp. Neurol. 51:160 (1976)

22. Shutack, J. G., Fox, W. W., Shaffer, T. H., Schwartz, J. G., and Moomjian, A. S.: Effect of low rate intermittent mandatory ventilation on pulmonary function of low birth weight infant. J. Pediatrics, 100: 779 (1982).

23. Siassi, B., Hodgman, J. E., Cabal, L., and Hon, E. H.: Cardiac and respiratory activity in relation to gestation and sleep states in newborn infants. Pediatr. Res., 13: 1163 (1979).

24. Stark, A. R. and Thach, B. T.: Mechanism of airway obstruction leading to apnea in newborn infant. J. Pediatr., 89: 92 (1976).

25. Steinschneider. A.: Nasopharyngitis and the sudden infant death syndrome. Pediatrics, 60: 531 (1977).

26. Thach. B. T., Brouillette, R. T., and Abu-Osbayk: Prevalence of mixed and obstructive apneic spell in preterm infants. Pediatr. Res., 14:637 (1980).

27. Thach, B. T. and Stark, A. R.: Spontaneous neck flexion and airway obstruction during apneic spells in preterm infants. Pediatrics, 94: 275 (1979).

28. Whitelaw, W. Derenne, J., Couture, J., and Milic-Emili, J. Adaptation of anesthetized man to breathing through an inspiratory resistor. J. Appl. Physiol., 41 (3): 285 (1976).

29. Zechman, F., Hall, F. G., and Hull, W. E.: Effects of graded resistance to tracheal airflow in man. J. Appl. Physiol., 10:356 (1957).

30. Requests for reprints should be addressed to: Dr. Soraya Abbasi, Department of Newborn Pediatrics, Pennsylvania Hospital, 8th and Spruce Streets, Philadelphia, Pennsylvania 19107.

31. Received for publication March 7, 1983

32. Accepted for publication September 19, 1983.

\title{
Erythrocyte 2,3-Diphosphoglycerate, $\mathrm{PO}_{2} 50 \%$, and Available Oxygen in Young Rabbits with and without Postnatal Fall in Hemoglobin
}

\author{
PER H. HOLTER, ${ }^{(22)}$ SVERRE HALVORSEN, AND HARALD E. REFSUM \\ Institute for Respiratory Physiology, and Department of Pediatrics, Ullevaal Hospital, Oslo, Norway
}

Summary

We determined erythrocyte 2,3-diphosphoglycerate (2,3DPG), $\mathrm{PO}_{2} 50 \%$, whole blood hemoglobin concentration, and available $\mathrm{O}_{2}$ from the 12 th to the 30 th $d$ after birth in two matched groups of young rabbits. One group received iron parenterally on the $12 \mathrm{th}, 15 \mathrm{th}$, and $18 \mathrm{th}$ d and the other received no iron supplement. In the untreated group there was a marked fall in hemoglobin concentration from the 12th to the 22nd $d$ and thereafter a marked increase to the initial level on the 30th $d$ whereas the iron-treated animals showed a marked rise in hemoglobin concentration from the 12th to the 22nd $d$, and a subsequent, slight decline from the 22 nd to the 30 th $\mathrm{d}$. The average values of $\mathrm{PO}_{2} 50 \%$ and 2,3-DPG, and the changes in $\mathrm{PO}_{2} 50 \%$ and 2,3-DPG were virtually identical for both groups. During the first period (12-22 d) there was a marked rise in both 2,3-DPG and $\mathrm{PO}_{2} 50 \%$ whereas in the second period $(22-30 \mathrm{~d})$ there was a somewhat smaller rise in 2,3-DPG and only a slight tendency toward a further rise in $\mathrm{Po}_{2} 50 \%$. In the untreated animals "available $\mathrm{O}_{2}$," reflecting the $\mathrm{O}_{2}$ delivery capacity of the blood, remained unchanged during the period of fall in hemoglobin concentration and showed a rise during the second period. In the iron-treated animals "available $\mathrm{O}_{2}$ " rose markedly during the first period, with iron-treatment, and remained unchanged during the second period. We conclude that the marked postnatal rise in 2,3-DPG and $\mathrm{Po}_{2} 50 \%$ in the rabbit seems to be independent of the changes in the hemoglobin concentration.

Abbreviations

2,3-DPG, 2,3-diphosphoglycerate

$\mathrm{Hb}$, hemoglobin concentration

Hct, hematocrit

MCHC, mean corpuscular hemoglobin concentration

$\mathrm{PO}_{2} 50 \%, \mathrm{PO}_{2}$ of blood at a hemoglobin $\mathrm{O}_{2}$ saturation of $50 \%$, corrected to $\mathrm{pH} 7.40$ and $\mathrm{PCO}_{2} 5.3 \mathrm{kPa}$.

$\mathrm{SO}_{2}$, hemoglobin $\mathrm{O}_{2}$ saturation 